\title{
A Tecnologia Digital e a Interdisciplinaridade como Constituintes de um Movimento Articulador de Disciplinas do Curso de Licenciatura em Matemática
}

\author{
Margarete Farias Medeiros ${ }^{1}$ \\ Elizete Maria Possamai Ribeiro² \\ Marleide Coan Cardoso ${ }^{3}$
}

\begin{abstract}
Resumo: Este artigo aborda reflexões e relato de uma experiência realizada envolvendo atividade interdisciplinar no curso de Licenciatura em Matemática. A atividade foi desenvolvida no ano de 2014-2, a partir da elaboração do planejamento das disciplinas, estudo e decisão das atividades que poderiam ser realizadas de forma interdisciplinar. As disciplinas envolvidas foram Laboratório de Prática de ensino-aprendizagem II, Estágio supervisionado IV, Estatística e Probabilidade. O conjunto de atividades planejadas está organizado nos registros da página virtual ${ }^{4}$, na qual, encontram-se o plano de ensino interdisciplinar, planejamento e apresentação das macroaulas, prova didática, planilha de avaliação da macroaula, orientações dos alunos, apresentação de livro e artigos, análise estatística e elaboração do texto de "Minha formação de professor de matemática". Com os dados gerados pela atividade avaliativa, aplicada em cada macroaula, foi realizada uma análise estatística envolvendo os conceitos abordados, esta apresentada pelos estudantes de estágio, sob a orientação dos professores das disciplinas. As atividades realizadas e, posteriormente, a análise dos resultados obtidos, à luz das teorias e autores aqui citados, sinalizam uma experiência com perspectivas de ampla contribuição aos professores e acadêmicos envolvidos, fomentando o conhecimento e a vivência de uma prática que superou as barreiras disciplinares.
\end{abstract}

Palavras-chave: Atividades Interdisciplinares. Formação do professor de Matemática. Tecnologias Digitais.

Abstract: The following article deals with reflections and an account of an experience involving interdisciplinary activity in the degree course in Mathematics. The activity was developed during the academic year 2014-2 from the planning of the disciplines, study and decision of the activities which could be carried out in an interdisciplinary way. The subjects involved were: Laboratory of Teaching-learning Practice II, Supervised Stage IV, Statistics and Probability. The set of planned activities is organized in the records of the virtual page. In

\footnotetext{
${ }^{1}$ Possui graduação em Ciências, com habilitação em Matemática pela Universidade do Extremo Sul Catarinense -UNESCDoutoranda do Programa Informática na Educação (UFRGS). Trabalha como professora no Instituto Federal Catarinense - Campus Sombrio, no curso superior de Licenciatura em Matemática - email margarete.medeiros@ifc.edu.br

${ }^{2}$ Possui graduação em Ciências com Habilitação em Matemática pela Universidade do Extremo Sul Catarinense - UNESC. Doutorado em Engenharia Mecânica pela Universidade Federal do Rio Grande do Sul (2006). Pós doutorado na Universidade de Bologna (Alma Mater Studiorum) no dipartimento di scienze e tecnologia agroambientali - UNIBO (2012). Email - elizete.ribeiro@ifc.edu.br

${ }^{3}$ Possui graduação em Licenciatura Em Ciências pela Universidade do Sul de Santa Catarina (1985) e Habilitação Matemática pela UnC (1997). Mestrado e Doutorado em Ciência da Linguagem pela Universidade do Sul de Santa Catarina (2003 e 2015 respectivamente). Email - marleide.cardoso@ifsc.edu.br

4 http://matinterdisciplinar.pbworks.com/w/page/83665909/FrontPage.
} 
this page we find the set of activities developed that include an interdisciplinary teaching plan, planning and presentation of macroaulas, didactic test, macroaula evaluation worksheet, student orientation, book and article presentation, statistical analysis and elaboration of " My Math Teacher Training ". With the data generated by the evaluative activity applied in each macroaula, a statistical analysis was carried out involving the concepts addressed in each class presented by the internship students under the guidance of the teachers involved in the disciplines. From the observations on the activities performed and the results obtained, in the light of the authors highlighted in this article, it is considered the accomplishment of an experience with great contribution to all the teachers and academics involved, generating knowledge and experience of a practice that surpassed the Disciplinary barriers.

Keywords: Interdisciplinary Activities. Teacher training in Mathematics. Digital Technologies

\section{Introdução}

Professores que atuam no processo de formação do futuro professor de matemática, nos últimos tempos, têm demonstrado grande preocupação no que diz respeito às atividades que os estudantes de licenciatura vivenciam durante 0 processo. Pautados nestas ideias os professores impulsionam a apresentação de atividades que possam desenvolver durante a prática docente dos acadêmicos. A formação docente é desafiadora, pois é preciso aliá-la a uma abordagem de sólida formação conceitual, sem se distanciar de uma abordagem metodológica, a fim de evitar dissociação entre teoria e prática.

A realização de práticas em Educação Matemática e a publicação destas contribuem para que ocorram avanços nos cursos de Licenciatura, uma vez que é a partir da socialização da divergência e convergência de ideias que se constrói o conhecimento.

Com base neste pressuposto, neste artigo, apresentar-se-á o relato de uma experiência realizada, considerando, principalmente, os aspectos que circundam a formação do professor de matemática.

Desse modo, os professores das disciplinas Laboratório de Prática de ensinoaprendizagem II, Estágio supervisionado IV, Estatística e Probabilidade, durante as atividades de planejamento, elaboraram um conjunto de atividades interdisciplinares Criar Educação, Criciúma, v. 8, nº, jan/jul 2019.- PPGE - UNESC 
com possibilidade de desenvolvimento no decorrer do semestre letivo. Para tal, partiu-se da problemática: Como envolver os estudantes de Licenciatura em Matemática, a partir de atividades interdisciplinares, durante 0 processo de formação?

Para responder à problemática proposta, parte-se da hipótese de que o acadêmico deve conhecer alternativas metodológicas que propiciem vivências da prática docente durante o processo de formação. Assim, é necessário, especificamente, planejar atividades interdisciplinares; aplicá-las em sala de aula; analisar os resultados a partir dos conceitos da estatística.

A metodologia que norteia essa experiência está relacionada à elaboração planejada do conjunto de atividades, a partir da proposta de um cronograma, bem como o controle de cada etapa de implementação. Conforme cronograma previamente elaborado e discutido com o grupo de alunos envolvidos, as atividades interdisciplinares aconteceram no decorrer do semestre, sendo que para cada etapa foi prevista a aplicação de um instrumento de avaliação (instrumento descrito no decorrer do artigo). Após a aplicação da macroaula seria aplicado uma prova que serviria para a realização da análise estatística da atividade (esta realizada pelos acadêmicos). Ulterior a essa etapa, os professores envolvidos fariam a análise as atividades.

O desenvolvimento de todas as atividades realizadas foi publicado numa página específica, criada para tal fim. A publicação de cada atividade estava condicionada ao processo de orientação e correções realizadas pelos professores envolvidos. Em nenhum momento houve atividades que fossem exclusivas de uma disciplina, até mesmo as orientações foram realizadas conjuntamente, em qualquer momento, sendo respeitados pelos docentes envolvidos, os encaminhamentos dados a cada aluno, uma vez que todos conheciam as atividades e 0 desenvolvimento das mesmas. No que tange às atividades, essas não foram as primeiras realizadas, representam uma segunda etapa de planejamento interdisciplinar, realizado anteriormente pelas professoras das disciplinas envolvidas.

O desenvolvimento e aperfeiçoamento das atividades interdisciplinares aplicadas no processo de formação de professores exigiram, das professoras, um Criar Educação, Criciúma, v. 8, nº1, jan/jul 2019.- PPGE - UNESC 
estudo mais detalhado do conceito de interdisciplinaridade e tecnologias, envolvendo o trabalho colaborativo e os conceitos da Estatística. Desta forma, a próxima seção consiste em apresentar os conceitos que fundamentaram teoricamente as atividades realizadas.

\section{Reflexões Teóricas}

A realização desta experiência implicou a utilização da interdisciplinaridade como uma questão de atitude dos professores envolvidos (FAZENDA, 2011), pois estes, sem preconceitos, partem do princípio de que todo conhecimento é igualmente importante.

Trabalhar de forma interdisciplinar exigiu dos participantes, inicialmente, dedicação para uma atividade de colaboração, de planejamento em conjunto, de desprendimento de ideias individuais, para um ideal em favor do conhecimento que o acadêmico iria construir. Japiassu (1976, p.75), acerca da prática interdisciplinar, afirma que a mesma:

(...) incorpora os resultados de várias especialidades, que toma de empréstimo a outras disciplinas certos instrumentos e técnicas metodológicos, fazendo uso dos esquemas conceituais e das análises que se encontram nos diversos ramos do saber, a fim de integrarem e convergirem, depois de terem sido comparados e julgados.

Os professores das disciplinas envolvidas abriram-se às mudanças, para inovações, para enfrentamento às situações novas, aos desafios que a interdisciplinaridade provoca. Trabalharam de forma articulada, mostrando que uma prática interdisciplinar exige planejamento dos professores, tanto antes quanto durante o processo, além de um processo avaliativo para cada etapa planejada. Com base nisso, entende-se que a prática concebida neste artigo confirma-se como uma "ação pedagógica" (BICUDO, 1993), e que por essa razão deve se transformar em pesquisa. Para tanto, nesta ação, buscaram-se dados nas atividades realizadas, a fim de atingir os objetivos estabelecidos inicialmente.

A prática interdisciplinar é um movimento importante de articulação entre 0 ensinar e o aprender (THIESEN, 2008) e, portanto, entende-se como uma forma de interligar, ou mesmo de mesclar as disciplinas, de modo que elas trabalhem juntas,

Criar Educação, Criciúma, v. 8, nº1, jan/jul 2019.- PPGE - UNESC 
proporcionando a ampliação da visão do acadêmico sobre como poderá ser sua prática enquanto professor de Matemática.

Fazenda (2011, p.11) afirma que "interdisciplinaridade não se ensina e não se aprende, apenas vive-se, exerce-se e, por isso, exige uma nova pedagogia, a da comunicação." À luz desse conceito, as professoras das disciplinas entenderam que o acadêmico de licenciatura em Matemática deveria exercer e viver esta prática em sua formação, oportunizando o "fazer interdisciplinar". Em troca, provocar-se-ia, no licenciando, no exercício da docência na Educação Básica, o gosto pelo trabalho interdisciplinar.

Além disso, observou-se que a interdisciplinaridade utilizada nesta prática, contemplaria alguns os objetivos traçados por Fazenda (2011), considerando o valor e a aplicabilidade como meio para conseguir a formação geral e profissional; incentivo à formação de pesquisadores e pesquisas; superar a dicotomia entre o ensino e a pesquisa; como condição para uma educação permanente; como forma de compreender e modificar o mundo. "(...) Uma interdisciplinaridade com vistas a novos questionamentos, novas buscas, enfim, para uma mudança na atitude de compreender e entender" Fazenda (2011, p.84).

Considerou-se que desenvolvimento de atividades interdisciplinares poderia ser facilitado e essas atividades poderiam ser compartilhadas pelo uso de tecnologia digital, pois com a criação de um ambiente virtual colaborativo, foi possível proporcionar, tantos aos estudantes como aos professores, o registro e a disponibilização das atividades desenvolvidas, das discussões e reflexões sobre as atividades, dos textos criados, dos modelos de aulas, em fim, de uma série de realizações interdisciplinares. Para tanto, os envolvidos apoiaram-se nos estudos de Costa e Fiorentini (2008), uma vez que os autores já realizaram estudos com a introdução das tecnologias digitais na prática escolar, mediadas pelo trabalho colaborativo e reflexivo de um grupo de professores. A partir desse estudo, os referidos autores afirmam que esta forma de trabalho pode desencadear um processo de mudança na cultura docente e escolar.

Atualmente, vive-se a cultura do virtual (BASSO e GRAVINA, 2012). Utilizarse dessa tecnologia digital se faz essencial no que compreende à Criar Educação, Criciúma, v. 8, nº 1, jan/jul 2019.- PPGE - UNESC 
interdisciplinaridade, pois o ambiente criado é utilizado por todos aqueles que têm acesso à internet, atingindo um número maior de pessoas, além dos estudantes do curso em questão.

O trabalho interdisciplinar lembra um pouco o trabalho cooperativo no ambiente virtual, no qual profissionais de diferentes áreas contribuem nas reflexões, e que possivelmente podem resultar em descobertas que irão beneficiar a todos os integrantes destas discussões. É uma prática de estabelecer as interseções, de diagnosticar as defasagens e verificar o que cada um pode contribuir para resolver os problemas encontrados (RIBEIRO, MEDEIROS e CARDOSO, 2014, p.4).

Diante dos avanços tecnológicos, torna-se essencial uma nova cultura profissional, que deve priorizar novos conhecimentos e olhares ao processo de formação do professor (BORBA, ALMEIDA e CHIARI, 2015). Desse modo, considera-se que esta nova cultura profissional perpassa pela colaboração em ambientes virtuais.

\section{Atividades Interdisciplinares}

A despeito do curso de Licenciatura em Matemática, instituiu-se entre os professores, mesmo que informalmente, a cultura de socialização das atividades desenvolvidas nas disciplinas, com um olhar voltado às discussões. Vale lembrar que essa prática não nasceu neste momento, estava presente em semestres anteriores, porém de forma informal.

No semestre de 2014-2, foi decidido, na fase de planejamento das disciplinas, formalizar estas conversas a partir do planejamento e registro das atividades. Então, chegou-se à conclusão de que a implementação da prática interdisciplinar envolveria as disciplinas de Laboratório de prática e ensino-aprendizagem II, Estágio Supervisionado IV, Estatística e Probabilidade, já que as mesmas constituem o currículo da oitava fase do curso de Licenciatura em Matemática.

As atividades foram planejadas antes do início do semestre, procurando estabelecer relações entre as disciplinas, ou seja, as práticas deveriam estar organizadas de modo a promover a interdisciplinaridade. Por essa razão, foi criada

Criar Educação, Criciúma, v. 8, nº 1, jan/jul 2019.- PPGE - UNESC 
uma página do tipo pbworks ${ }^{5}$, na qual foram postadas todas as atividades desenvolvidas pelos acadêmicos durante o semestre. A página encontra-se ativa no link http://matinterdisciplinar.pbworks.com/w/page/83665909/FrontPage.

A FrontPage, abaixo, apresentada na Figura (1), mostra uma interface voltada à prática em questão. Nela apresentam-se as ações realizadas durante a experiência interdisciplinar. Procurou-se, já no primeiro momento, chamar a atenção dos acadêmicos para o trabalho articulado entre as disciplinas envolvidas e, da mesma forma, mostrar que a prática interdisciplinar exige planejamento dos professores, tanto antes quanto durante o processo. Assim, são apresentados os planejamentos de ensino das disciplinas no primeiro link da FrontPage, com objetivos interdisciplinares.

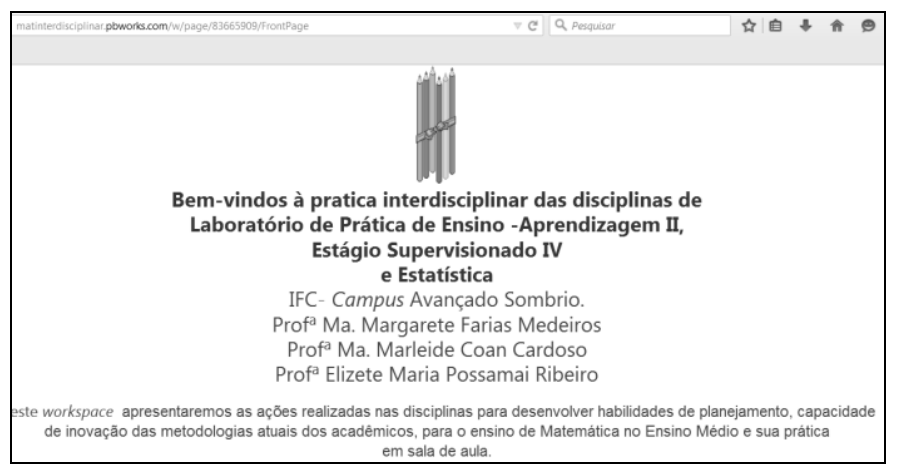

Figura 1 - FrontPage Interdisciplinar

Fonte - http://matinterdisciplinar.pbworks.com/w/page/83665909/FrontPage

Ainda na FrontPage do trabalho interdisciplinar, vê-se, conforme Figura (2), os links que direcionam às postagens referentes às atividades desenvolvidas, tais como: macroaulas ${ }^{6}$, prova didática ${ }^{7}$, planos de aula, planilha de avaliação, orientações, dentre outras.

Nas seções que seguem far-se-á uma descrição com mais detalhes de cada atividade realizada.

\footnotetext{
5 pbworks.com

${ }^{6}$ Termo utilizado para designar uma aula com maior duração, ou seja, em torno de 3 horas. Foi criado pelo grupo de professores da área específica da Matemática.

${ }^{7}$ Termo utilizado para designar um recorte de uma aula, ou seja, com duração em torno 30 minutos.
}

Criar Educação, Criciúma, v. 8, nº, jan/jul 2019.- PPGE - UNESC 


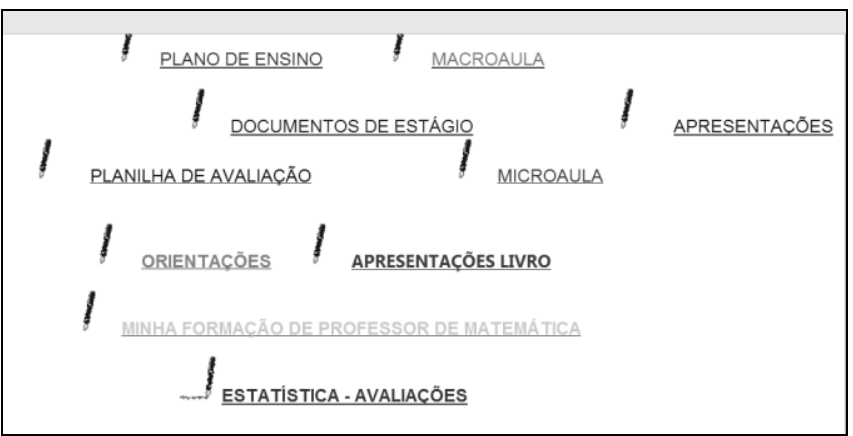

Figura 2 - Links das atividades desenvolvidas

Fonte - http://matinterdisciplinar.pbworks.com/w/page/83665909/FrontPage

\subsection{Orientações e Coorientações}

Para dar subsídio à disciplina de estágio IV, as orientações e coorientações deveriam estar de acordo com as normas do estágio, as quais já estavam definidas no PPC do curso de Licenciatura em Matemática do campus.

Com base nisso, foi estabelecido que os orientadores deveriam ser professores atuantes no curso de Licenciatura da área específica da Matemática, visto que seriam eles, juntamente com os coorientadores, os responsáveis pela revisão dos planos de aula desenvolvidos nos campos de estágio. Destarte, a definição dos orientadores e coorientadores foi efetivada por meio de sorteio conforme Quadro 1, em uma reunião do Núcleo Desenvolvimento Estruturante (NDE).

O orientador deveria estabelecer um plano de trabalho junto ao orientando, registrando as datas e duração dos encontros, em que se desenvolvia a orientação. Também cabia ao orientador fazer a leitura e correção dos planos de aula que seriam utilizados nos campos de atuação de estágio; visita ao campo de estágio para observação de regência; leitura do relatório de estágio.

Competia ao coorientador fazer a leitura do relatório de estágio, observando melhorias na redação, organização técnica e adequação às normas da ABNT vigente.

Criar Educação, Criciúma, v. 8, nº, jan/jul 2019.- PPGE - UNESC 


\begin{tabular}{|c|c|c|}
\hline \multicolumn{3}{|l|}{ ESTÁGIO SUPER VISIONADO IV } \\
\hline Orientadores & Orientadores & $\begin{array}{l}\text { Co-orientação dos } \\
\text { relatórios } \\
\text { e correçẫo relatório }\end{array}$ \\
\hline Alvaro Maciel & $\begin{array}{l}\text { Elizete Maria Possamai } \\
\text { Ribeiro }\end{array}$ & Deivi de Oliveira Scarpari \\
\hline Erodiades Daboit Possamai & Lucas Spillere Barchinski & Gerson Luis da Luz \\
\hline Edna da Silva Al bino & $\begin{array}{l}\text { Margarete Farias } \\
\text { Medeiros }\end{array}$ & Carla Sofía Dias Brasil \\
\hline Edna de Borba Cardoso & Valdirene da Rosa Rocho & Iris Weiduschat \\
\hline Helen Savi Mondo de Oliveira & Lucas Spillere Barchinski & $\begin{array}{l}\text { Jose Leocadio Cabral } \\
\text { Neto }\end{array}$ \\
\hline Katelyn Luzia dos Santos Daboit & $\begin{array}{l}\text { Margarete Farias } \\
\text { Medeiros }\end{array}$ & $\begin{array}{l}\text { Maria Emilia Martins da } \\
\text { Silva }\end{array}$ \\
\hline Mara Cristina Baltazar & Marleide Coan Cardo so & Emerson Luis Monsani \\
\hline Mariani Constante de Jesus & $\begin{array}{l}\text { Margarete Farias } \\
\text { Medeiros }\end{array}$ & $\begin{array}{l}\text { Rosemary de Fátima de } \\
\text { Assis Domingos }\end{array}$ \\
\hline Natalia Lummertz & Valdirene da Rosa Rocho & $\begin{array}{l}\text { Maria Emilia Martins da } \\
\text { Silva }\end{array}$ \\
\hline Nebia Mara de Souza & $\begin{array}{l}\text { Elizete Maria Possamai } \\
\text { Ribeiro }\end{array}$ & $\begin{array}{l}\text { Rosemary de Fátima de } \\
\text { Assis Domingos }\end{array}$ \\
\hline Patricia Becker Delfino & Marleide Coan Cardoso & Gerson Luis da Luz \\
\hline Sabrini Micheli da Silva dos Anjos & Valdirene da Rosa Rocho & Carla Sofia Dias Brasil \\
\hline Susana Pereira da Cunha de Matos & Marleide Coan Cardo so & Iris Weiduschat \\
\hline Suzana Scandolara Selau & Lucas Spillere Barchinski & $\begin{array}{l}\text { Jose Leocadio Cabral } \\
\text { Neto }\end{array}$ \\
\hline Vanessa da Silva Pires & Marleide Coan Cardo so & Saulo Zulmar Veira \\
\hline $\begin{array}{l}\text { Zilmara Raupp de Quadros de } \\
\text { Oliveira }\end{array}$ & Lucas Spillere Barchinski & Emerson Luis Monsani \\
\hline
\end{tabular}

Quadro 1- Orientadores e Coorientadores da disciplina de estágio supervisionado IV Fonte - Disciplina de estágio supervisionado IV

\subsection{Macroaula, Microaula e Prova Didática}

Uma atividade de grande importância foi a execução da macroaula. A apresentação era realizada ora na disciplina de Estágio IV, ora na disciplina de Laboratório de Prática de Ensino e Aprendizagem II, com a presença das professoras das disciplinas. A macroaula (Figura 3) diz respeito à apresentação com um conteúdo de Ensino Médio, sorteado entre os acadêmicos no início do semestre, com data prevista de execução.

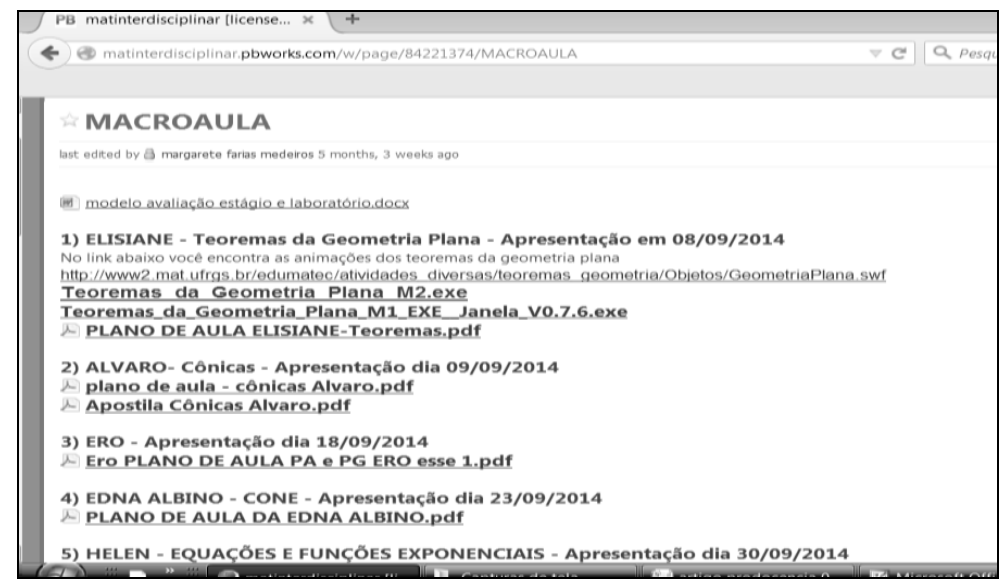

Figura 3 - Recorte dos Temas das macroaulas Fonte - http://matinterdisciplinar.pbworks.com

Criar Educação, Criciúma, v. 8, nº1, jan/jul 2019.- PPGE - UNESC 
O acadêmico desenvolveu o tema com introdução, desenvolvimento e conclusão, incluindo uma avaliação para a turma com o instrumento de prova, com duração em torno de três horas. Cada acadêmico era avaliado pelos próprios colegas e também pelos professores presentes, sendo obtidas duas médias que compunham duas notas do semestre em questão. A partir disso, foi criada uma planilha para registro de tal avaliação.

A realização da macroaula, também com data prevista para execução, exigiu do acadêmico a apresentação da prova didática, que consistia em um recorte da macroaula. A prova didática tinha duração de 30 minutos, e foi apresentada a uma banca avaliadora composta por três professores integrantes do curso: um do núcleo específico, um do núcleo pedagógico e outro do núcleo geral. Avaliados, os acadêmicos obtinham uma média que compunha uma das notas de avaliação do semestre.

As macroaulas foram desenvolvidas em sala de aula envolvendo os temas previamente definidos por sorteio. A metodologia de apresentação de cada macroaula correspondeu ao desenvolvimento da aula, a partir de uma tendência em Educação Matemática. Como a atividade foi desenvolvida na última fase do curso, os estudantes já haviam estudado de forma detalhada cada tendência em Educação Matemática bem como suas implicações no ensino da Matemática, além de sua abordagem enquanto possibilidade metodológica. As macroaulas eram avaliadas por todos os participantes da aula, possibilitando aos estudantes, neste processo, reconhecer os critérios de avaliação que devem estar presentes durante a prática docente. Para a realização da avaliação, a partir de um instrumento previamente elaborado pelas professoras envolvidas, os estudantes foram orientados sobre a importância da prática docente reflexiva para a valorização dos aspectos relevantes de uma aula, bem como da identificação de aspectos que, supostamente, podem ser melhorados. O instrumento corresponde a uma planilha, descrita na próxima seção, desenvolvida por um estudante do curso durante a disciplina de estágio, objetivando simplificar a quantificação dos critérios. Para a realização do processo avaliativo da apresentação das macroaulas, foi realizado um seminário sobre a importância da avaliação em todas as dimensões da prática docente. Vale ressaltar que o intuito Criar Educação, Criciúma, v. 8, nº1, jan/jul 2019.- PPGE - UNESC 
não residia apenas em apontar pontos que exigissem melhorias, mas também no que compreende à valorização e incentivo para -buscar novas possibilidades metodológicas.

\subsection{Planilha de avaliação}

$\mathrm{Na}$ apresentação da macroaula, como dito anteriormente, os acadêmicos foram avaliados pelos próprios colegas e pelos professores presentes. Cada acadêmico foi avaliado na apresentação da macroaula e para facilitar a avaliação, foi criada uma planilha por um acadêmico ${ }^{8}$ do curso. Portanto, o processo de avaliação transcorreu com transparência. Os acadêmicos eram avaliados e também avaliadores das macroaulas apresentadas.

$\mathrm{Na}$ Figura (4) são apresentados os critérios utilizados para a avaliação da macroaula: planejamento, execução da aula, aspecto didático, contextualização do tema e avaliação do trabalho.

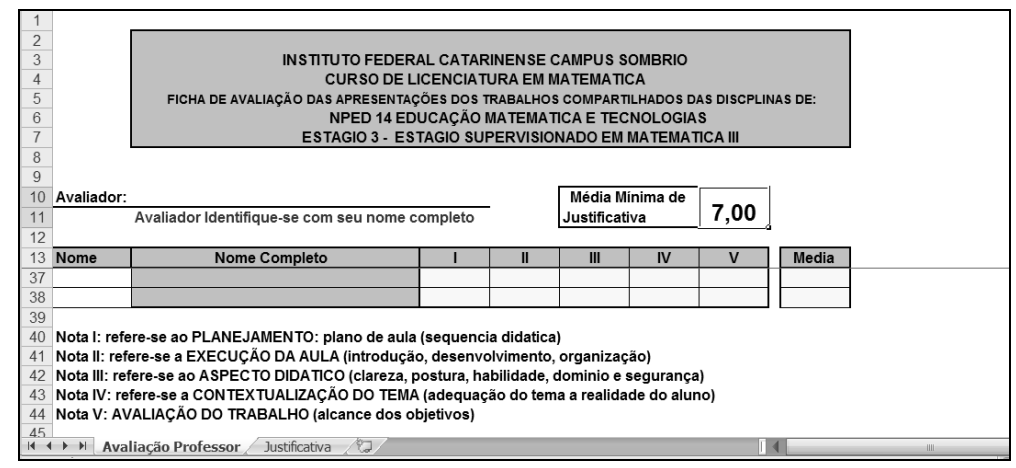

Figura 4 - Planilha de avaliação

Fonte - Planilha do Excel criada para a avaliação

Em relação ao planejamento, foi avaliada a sequência didática no plano de aula, com os objetivos previstos, tanto específicos quanto geral, a metodologia, o desenvolvimento, os recursos utilizados e os critérios e instrumentos de avaliação da macroaula. Na execução da aula, foram avaliados: introdução, desenvolvimento e também a organização da aula. Quanto ao aspecto didático, observou-se a clareza, postura, habilidade, domínio e segurança do acadêmico. No que tange à

\footnotetext{
${ }^{8}$ Evaldo Pagani, acadêmico da primeira turma ingressante no curso de Licenciatura em Matemática do Campus.

Criar Educação, Criciúma, v. 8, nº1, jan/jul 2019.- PPGE - UNESC
} 
contextualização, verificou-se se o tema estava adequado ao nível do ensino, se estava de acordo com a realidade do aluno de ensino médio. E para finalizar a avaliação, observou-se o alcance dos objetivos traçados no planejamento de aula.

Os dados de avaliação de cada acadêmico foram lançados nos itens de I a V, conforme planilha na Figura (4), nos campos dos professores avaliadores e dos acadêmicos avaliadores. Se houvesse a atribuição de uma nota inferior a sete $(7,0)$, o avaliador deveria justificar a nota atribuída, fazendo uma análise de acordo com os critérios estabelecidos. Ao final, foram obtidas duas médias, uma em relação às notas dos professores avaliadores e outra em relação às notas dos acadêmicos avaliadores.

\subsection{Apresentações Livro}

Dentre as leituras sugeridas para dar suporte aos trabalhos dos acadêmicos, buscou-se fundamentação no livro da Coleção Formação de Professores "O Laboratório de Ensino de Matemática na Formação de Professores" (LORENZATO, 2009), que foi estudado na disciplina de Laboratório de Prática de Ensino e Aprendizagem II. O livro em questão é composto por uma série de artigos que tratam da formação do professor, metodologias, utilização de tecnologias, implantação de laboratório de educação matemática, dentre outros. A ideia foi dividir os artigos entre os acadêmicos, formando duplas, sendo que cada dupla apresentou o artigo destacando a importância do conteúdo para a formação deles.

$\mathrm{Na}$ Figura (5), apresentam-se os links que direcionaram as apresentações dos artigos estudados.

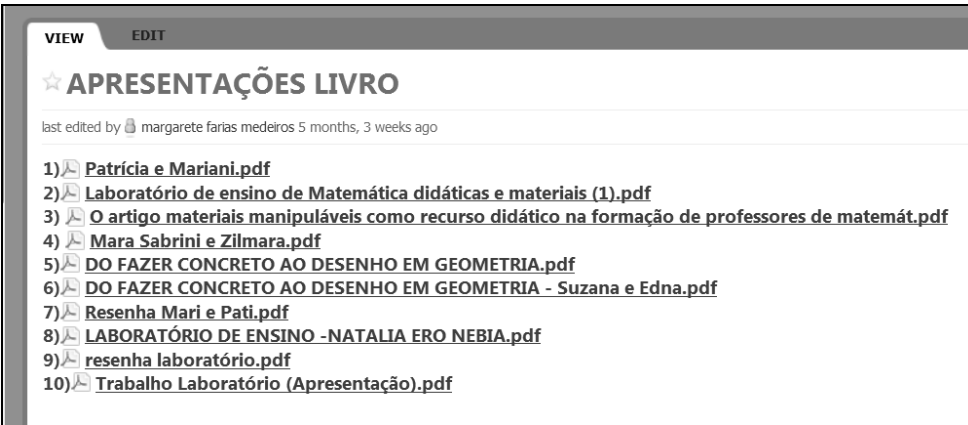

Figura 5 - Apresentações de artigos

Criar Educação, Criciúma, v. 8, nº 1, jan/jul 2019.- PPGE - UNESC 
Entre o conjunto de atividades planejadas para a disciplina de Estágio Supervisionado IV, estava a elaboração do artigo final de conclusão do curso. Para a elaboração do artigo, cada estudante teve um orientador cuja formação deveria estar relacionada ao tema proposto ao desenvolvimento do artigo de conclusão. Assim, a parte referente ao desenvolvimento de leituras no semestre deveria ter relação com o artigo. Com base nisso, foi decidido que cada estudante deveria socializar a fundamentação teórica do artigo em sala e aula, ou seja, compartilhar o conhecimento adquirido com os professores envolvidos na atividade interdisciplinar e com os colegas de turma. Esta proposta possibilitou ao curso de Licenciatura em Matemática o reconhecimento das diferentes tendências desenvolvidas ao longo do curso.

\subsection{Atividade em Estatística}

Para envolver a disciplina de Estatística e Probabilidade, observou-se que os dados obtidos nas avaliações realizadas pelos acadêmicos nas macroaulas poderiam compor dados estatísticos, (relacionados aos conteúdos trabalhados durante o semestre) como, por exemplo, rol, tabelas, distribuições de frequência, gráficos, medidas de posição, de dispersão, de assimetria e de curtose.

Os acadêmicos matriculados na disciplina de Estatística e Probabilidade realizaram a coleta dos dados que foram organizados em ordem crescente, isto é, em rol. Segundo Crespo (2002), a coleta de dados pode ser feita de forma direta ou indireta. A primeira, por meio de elementos informativos ou quando os dados são coletados pelo próprio pesquisador, a segunda é inferida de elementos conhecidos ou relacionados ao fenômeno estudado. A coleta de dados utilizada foi realizada de forma direta, uma vez que os dados foram coletados pelo pesquisador a partir das avaliações aplicadas. Após o levantamento, os dados foram tabulados e representados graficamente por meio de histograma e polígono de frequência.

Criar Educação, Criciúma, v. 8, nº, jan/jul 2019.- PPGE - UNESC 
Posteriormente, com os dados já tabulados e representados, foram estudadas as distribuições de frequência. Crespo (2002) denomina como distribuição de frequência o número de valores de uma variável pertencente a uma classe, e dá como elementos desta a Classe, os Limites de Classe, a Amplitude de um Intervalo de Classe, a Amplitude Total da Distribuição, a Amplitude Amostral, o Ponto Médio de uma Classe, a Frequência Simples ou Absoluta, Frequência Relativa, Frequência Acumulada e Frequência Acumulada Relativa.

Esse estudo foi possível descrever os grupos dos valores que uma variável pode assumir, localizar, assim, maior concentração de valores de certa distribuição. Conforme Crespo (2002), para ressaltar as tendências características de cada distribuição, é necessário introduzir conceitos que se expressam através de números e que permitam traduzir essas tendências. Tais conceitos são denominados elementos típicos da distribuição e são as medidas de posição, medidas de dispersão, medidas de assimetria e medidas de curtose.

Dentre os elementos típicos, destacam-se as medidas de posição, em que as mais importantes são a Média, a Mediana e a Moda, pois se destacam pelo fato de os dados se agruparem em torno dos valores centrais. Outras medidas de posição são os quartis e percentis.

A variância e o desvio padrão são medidas que fogem da falha da amplitude total instável, pois eles levam em consideração a totalidade dos valores da variável. Todavia, o desvio padrão ainda possui algumas dificuldades e limitações, as quais são contornadas com a utilização do coeficiente de variação. E por último, destacase a curtose, que é o grau de achatamento de uma distribuição em relação a uma distribuição padrão. Na Figura (6), encontram-se os links que direcionam aos trabalhos desenvolvidos pelos acadêmicos na disciplina de Estatística.

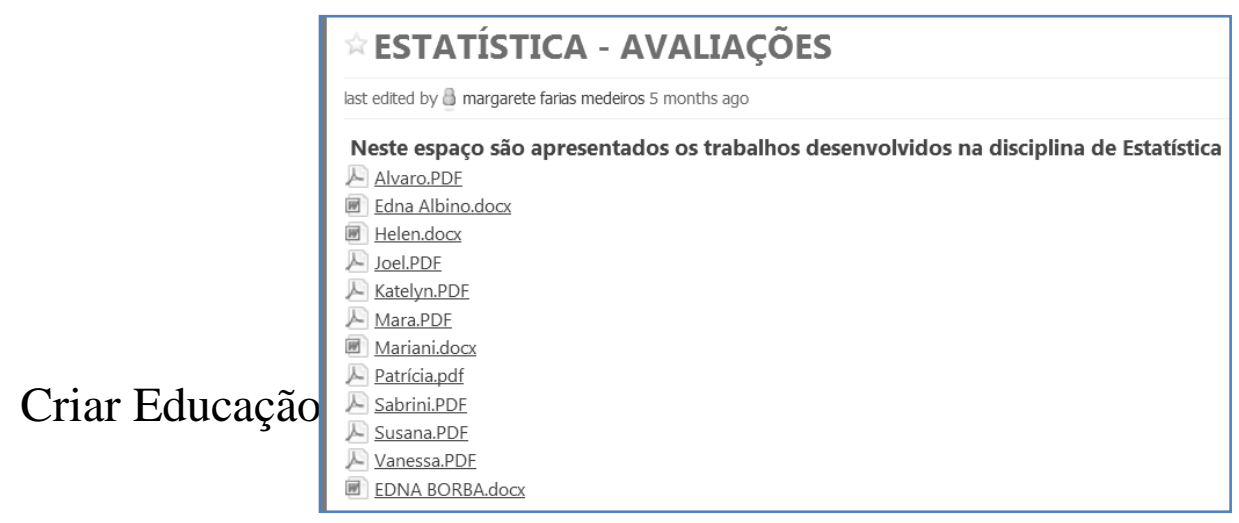


Figura 6 - Atividades em Estatística

Fonte: http://matinterdisciplinar.pbworks.com

A Figura (7) apresenta um recorte de um trabalho em que o acadêmico coloca em prática os conhecimentos em Estatística, utilizando dados das disciplinas de Laboratório de Prática de Ensino e Aprendizagem II e Estágio Supervisionado IV.

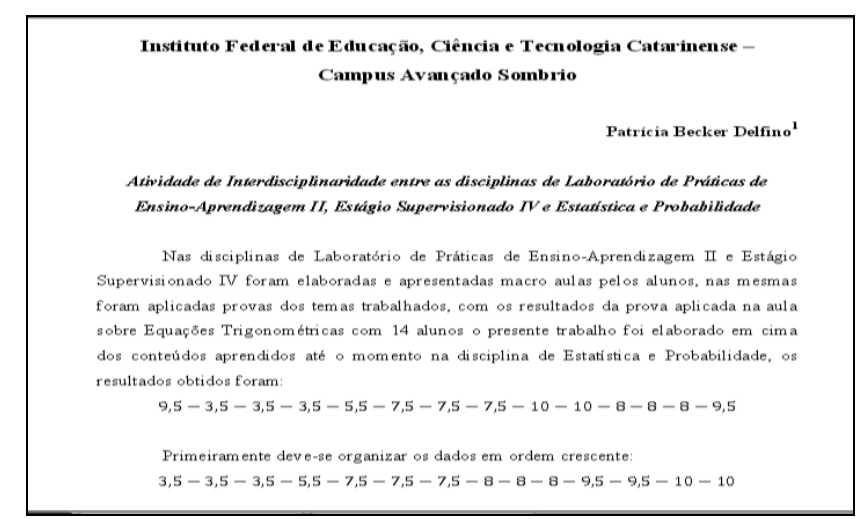

Figura 7 - Recorte do trabalho em Estatística

Fonte - http://matinterdisciplinar.pbworks.com

Neste caso, o acadêmico, após agrupar as notas por intervalos de classe, observou que a classe que obteve maior frequência foi a de notas seis a oito. Portanto, com base no conhecimento referente ao conteúdo tratado - equações trigonométricas, com um percentual de $72 \%$ de notas acima de sete, considerou-se que os alunos obtiveram um bom rendimento.

\subsection{Minha formação de professor de matemática}

Esta seção corresponde à produção dos estudantes, no que diz respeito à avaliação feita pelo acadêmico em relação ao curso de Licenciatura em Matemática, no processo final de formação. Para a produção deste texto, os estudantes foram orientados que deveriam levar em consideração toda a trajetória enquanto estudante da educação básica e também durante o curso de licenciatura em matemática. Desse modo, o acadêmico deveria refletir sobre a vida escolar até a Licenciatura em Matemática e produzir um texto que representasse as intenções de atuação como docente de matemática. E ainda: refletir acerca de quais as características

Criar Educação, Criciúma, v. 8, nº, jan/jul 2019.- PPGE - UNESC 
necessárias ao professor, sua atuação enquanto um profissional docente de matemática, o que representa ser um "professor de matemática".

Ao ler os textos produzidos pelos estudantes no final da formação inicial de licenciatura em Matemática, destacam-se alguns aspectos importantes, vivenciados por eles, durante o processo de formação, constituindo um ideário à formação de professor de matemática. Dentre as falas dos acadêmicos, destacam-se, abaixo, algumas importantes para reflexão acerca da formação inicial de professores.

- "Durante minha formação, pensei diversas vezes qual tipo de professor eu queria ser. Aquele que tive durante o ensino fundamental, em que apenas passava o conteúdo e não se importava com o aprendizado dos alunos, ou o que tenho hoje, que se importa com o aprendizado de seus alunos e busca sempre novas maneiras de explicar o conteúdo. Cheguei à conclusão de que quero ser um professor que se preocupa com os alunos, que busca novas técnicas de ensino para atrair a atenção do educando".

- "Posso afirmar que vou levar para sempre o IFC na memória, pois a cada semana pude perceber o quanto cresci, o quanto amadureci e o quanto me interessei em querer saber sempre mais. Sempre tive o cuidado de chegar ao IFC com um conhecimento e sair com algo a mais".

- "Aprender a ensinar parece tão fácil, mas é muito complexo. Muito bom quando se está no papel de aluno, porém quando o aluno toma lugar do professor, fica difícil. A sensação de não conseguir realizar as atividade invade, mas aos poucos, as coisas vão se desenrolando e dando certo, com a orientação dos professores. Outro aspecto importante é a troca de experiência com os colegas".

- "Encontrei neste percurso, várias características diferentes entre os professores. Algumas eu considero pouco aproveitável; nunca vou esquecer, ficarão somente para mim, pois considero que não devem ser seguidas. Por outro lado, a maioria dos professores apresentam características que internalizei e resgatarei, sempre que precisar, para Criar Educação, Criciúma, v. 8, nº1, jan/jul 2019.- PPGE - UNESC 
minha atuação. Em suma, todo o curso de licenciatura em matemática contribuiu e muito para minha formação, com novas aprendizagens, indicando vários recursos que podem ser utilizados diariamente em sala de aula".

- "Como posso avaliar meu aluno sabendo que cada um possui características individuais, por fim aprendemos, vimos em sala de aula vários caminhos que podemos seguir. Para ser um bom professor, devemos desviar de alguns caminhos".

- "Acredito que minha formação foi importante e de qualidade, já que todos os professores se envolveram cada qual da sua maneira, na sua disciplina. Procuraram trazer para a sala de aula todas as informações, conteúdos, didáticas, planejamentos e tecnologias para oferecer ao acadêmico os conhecimentos que sustentem a profissão docente".

- "Acredito que minha formação acadêmica promoveu uma completa mudança em minha forma de pensar, não somente no âmbito profissional, mas também em minha formação enquanto sujeito na sociedade. Com relação à formação, enquanto professor tenho plena certeza de que esta proporcionou a construção de uma base sólida, não somente de conhecimentos matemáticos, mas também pedagógicos e humanos para a atuação enquanto professor da educação básica".

O relato aqui apresentado é palco de acalorada discussão no que diz respeito à formação de professores. Ao analisar as respostas dadas pelos estudantes do curso de Licenciatura envolvidos no desenvolvimento da atividade interdisciplinar, observa-se que foi possível alcançar formação mais ampla, para além da importância dos conceitos matemáticos desenvolvidos ao longo do curso, enfatizando todos os aspectos que constituem o processo de formação docente inicial. Os acadêmicos discutem, com muita propriedade, sobre a formação nas diferentes dimensões da prática docente. Todas as produções dos estudantes do ano de 2014-2 podem ser acessadas na íntegra, no endereço http://matinterdisciplinar.pbworks.com.

Criar Educação, Criciúma, v. 8, nº 1, jan/jul 2019.- PPGE - UNESC 


\section{Os Resultados}

Com base nos resultados, foi possível verificar que a atividade interdisciplinar proporcionou um envolvimento com mais particularidade dos professores das disciplinas de Laboratório de Prática de ensino-aprendizagem II, Estágio supervisionado IV, Estatística e Probabilidade. Todavia, vale lembrar que todos os professores do curso atuaram como coorientadores e orientadores do estágio de docência ou do artigo e conclusão do curso. Isso possibilitou a integração dos professores atuantes no curso fomentando o conhecimento dos envolvidos em relação às disciplinas ofertadas. Da mesma forma, oportunizou aos participantes a formação em docência pela vivência de um conjunto de atividades, ora como orientador ora como avaliador das mesmas.

Do mesmo modo, verificou-se que a criação da página virtual proporcionou um ambiente de colaboração em que os envolvidos contribuíram com discussões, planos de aulas, textos, indicação de sites. Esta criação contribuiu para que se atingissem os objetivos estabelecidos, oportunizando aos acadêmicos o acesso aos materiais disponibilizados na página e também provendo a discussão em torno da utilização dos mesmos. Essa foi uma das formas usadas para inserir a tecnologia digital na formação dos licenciandos, além da utilização de softwares e vídeos, para a produção das apresentações de macroaulas e prova didática.

Para a apresentação da macroaula, os estudantes apresentaram softwares novos, além de inúmeras metodologias envolvendo pequenas mídias, animações, materiais manipulativos, jogos, história da matemática, modelagem, entre outras metodologias de ensino.

Outra atividade que contribuiu significativamente, no que diz respeito ao envolvimento dos participantes, foi a leitura de livros e bibliografias relacionadas ao artigo de conclusão do curso. Os materiais em questão abordavam assuntos relacionados à formação do professor, à matemática aplicada, a tendências da educação matemática e inclusão, que foram importantes para dar subsídio à prática docente, tanto no que tange às atividades realizadas nas disciplinas do curso bem como às práticas nos campos de estágios, ou seja, a teoria dando suporte à prática. Criar Educação, Criciúma, v. 8, nº, jan/jul 2019.- PPGE - UNESC 
Considerando o conjunto de atividades interdisciplinares tais como as macroaulas, prova didática, leituras orientadas, criação da página virtual, participação no processo avaliativo, aplicação dos conceitos da estatística e a produção dos textos, considera-se que foi possível promover um processo de formação inicial e continuada diferenciado a todos os participantes. Estas atividades foram avaliadas em um encontro com os acadêmicos matriculados nas três disciplinas e seus respectivos professores. Naquele momento, os estudantes e professores expuseram, apresentando um breve resumo de suas trajetórias nestas disciplinas, durante o seminário de encerramento das atividades, suas ideias a respeito da prática interdisciplinar do curso de licenciatura.

\section{Considerações Finais}

Este artigo é resultado de uma experiência envolvendo a interdisciplinaridade no curso de Licenciatura em Matemática- Campus Avançado Sombrio, no ano de 2014. A experiência parte da constatação das professoras envolvidas sobre a necessidade de se possibilitar aos estudantes vivências interdisciplinares durante 0 processo de formação inicial de maneira que estas vivências passem a constituir a prática, quando em exercício da docência.

Ao realizar esta prática interdisciplinar, foi possível verificar alguns pontos que mereceram atenção especial no que tange aos acadêmicos matriculados nas as disciplinas que fizeram parte da experiência. Houve a necessidade da realização de adaptação das atividades planejadas uma vez que, no curso superior, a matrícula dos estudantes é por disciplina e nem sempre estão regulares com o curso ou frequentem todas as disciplinas. À medida que se identificava os estudantes, as professores realizavam as adaptações da atividade de acordo com a sua matricula.

Outro fator importante para o sucesso da prática em questão diz respeito aos professores, que desejaram desenvolver um projeto interdisciplinar, colocando-se à disposição, a fim de promover a integração. Vale ressaltar que os professores, dedicando muito tempo para planejamento, buscaram, no intuito de superar o individualismo comum da disciplina, o conhecimento dos conceitos relacionados aos conteúdos abordados nas disciplinas envolvidas. O desenvolvimento da atividade Criar Educação, Criciúma, v. 8, nº 1, jan/jul 2019.- PPGE - UNESC 
oportunizou o rompimento das barreiras existentes nas disciplinas, fazendo com que os professores tivessem uma visão ampliada do processo docente, necessária ao desenvolvimento de uma atividade interdisciplinar. Ainda, verificou-se que a atividade propiciou, no que compreende ao semestre letivo, dinamicidade diferenciada da realidade, pois estudantes e professores desenvolveram as atividades, além das exigidas pela disciplina, que implicaram conhecimentos referentes a outras áreas do saber, visando enriquecimento mútuo e cumplicidade de ações.

Neste contexto, após o desenvolvimento da atividade, emergiram aspectos importantes, que potencializaram o processo de formação para além da formação disciplinar, tais como a possibilidade de que o licenciando possa ser um multiplicador da interdisciplinaridade; ter ciência de que as ações no mundo real são interdisciplinares; possa aplicar em projetos de pesquisa e extensão; inserir a tecnologia digital como auxílio à prática pedagógica; superar a fragmentação e promover a transposição didática.

Outro aspecto importante a ser considerado, consiste no envolvimento dos estudantes no cumprimento das atividades que foram organizadas no inicio do semestre, o contrato didático firmado entre as partes (professores e estudantes) visando à melhoria do ensino e da aprendizagem. A interdisciplinaridade serviu como pano de fundo e sustentação para a atividade, que se fez presente na práxis, estabelecendo elo entre teoria e prática no curso de licenciatura, proposta almejada pelas professoras que desenvolveram a atividade.

Desse modo, por meio da interdisciplinaridade, foi possível perceber, nos professores e acadêmicos, um fortalecimento na integração entre a prática pedagógica como também interação entre os colegas, uma vez que se estabeleceu conexão entre diferentes disciplinas, independente dos temas/assuntos tratados nelas.

Com base no que foi proposto, a atividade desenvolvida corroborou que a interdisciplinaridade pode ser aplicada nos cursos de licenciaturas, entretanto é premente que os professores inovem, modifiquem velhas práticas, dando espaço a metodologias diferenciadas, como foi proposto aqui. Nesse viés, é plausível, Criar Educação, Criciúma, v. 8, nº 1, jan/jul 2019.- PPGE - UNESC 
trabalhar um tema em várias disciplinas, fazendo com que o objeto de estudo seja analisado sob várias nuanças, no que se refere às infinitas áreas do conhecimento.

\section{Referências}

CRESPO, Antônio Arnot. Estatística Fácil. São Paulo: Saraiva, 2008.

BICUDO, M. A. V. Pesquisa em educação matemática. Pró-posições, Campinas, v. 4, n. 1, p. 18-23, mar., 1993.

BASSO, Marcus Vinicius de Azevedo; GRAVINA, Maria Alice. Mídias Digitais na Educação Matemática. In: GRAVINA, Maria Alice et al (Org.) Matemática, Mídias Digitais e Didática: Tripé para formação do professor de Matemática. Porto Alegre: Evangraf, 2012.p. 11-35.

BORBA, M.C.; ALMEIDA, H.F.R.L.; CHIARI, A.S.S. Tecnologias Digitais e a relação entre teoria e prática: uma análise da produção em trinta anos do BOLEMA. Disponível em: < http://www.periodicos.rc.biblioteca.unesp.br/index.php/bolema/article/view/9835/7292 > Acesso em: 2 jun.2016.

COSTA, G.L.M.;FIORENTINI, D. Mudança da Cultura Docente em um Contexto de Trabalho Colaborativo de Introdução das Tecnologias de Informação e Comunicação na Prática Escolar Disponível em: < http://www2.rc.unesp.br/bolema/?q=node/109>. Acesso em: 16 jun.2016.

FAZENDA, Ivani Catarina Arantes. Integração e interdisciplinaridade no ensino brasileiro. 6를 ed. São Paulo: Edições Loyola, 2011.

LORENZATO, Sérgio (Org.). O Laboratório de Ensino de Matemática na Formação de Professores. Campinas: Autores Associados, 2009.

JAPIASSU, Hilton. Interdisciplinaridade e Patologia do Saber. Rio de Janeiro: IMAGO, 1976.

RIBEIRO, E.M.P.; MEDEIROS, M.F.; CARDOSO, M.C. Limites e Possibilidades de um Trabalho Interdisciplinar. Disponível em

<http://linguagem.unisul.br/paginas/ensino/pos/linguagem/eventos/simfop/artigos_VI \%20sfp/Elizete\%20Maria\%20Possamai\%20Ribeiro_et_al.pdfs Acesso em: 16 jun.2016

THIESEN, Juarez da Silva. A interdisciplinaridade como um movimento articulador no processo ensino-aprendizagem. In: Revista Brasileira de Educação. Rio de Janeiro: ANPEd, v.13, n.39, p.545-553, set./dez.2008.

Criar Educação, Criciúma, v. 8, nº1, jan/jul 2019.- PPGE - UNESC 
Recebido em setembro de 2018 Aprovado em fevereiro de 2019

Criar Educação, Criciúma, v. 8, nº 1, jan/jul 2019.- PPGE - UNESC 